\title{
Severe Plastic Deformation of Amorphous Alloys
}

\author{
Ádám Révész and Zsolt Kovács \\ Department of Materials Physics, Eötvös University, Budapest, H-1518, P.O.B. 32, Budapest, Hungary
}

Bulk metallic glasses having a disordered amorphous structure have been in the focus of recent intensive materials research due to their special mechanical properties, however, these materials exhibit brittleness in conventional unconstrained deformation modes. High-pressure torsion as a special severe plastic deformation method, which applies constraints on the material, can induce significant plasticity in metallic glasses. Apart, the deformation can promote structural changes in the glass, such as anisotropy and nanocrystallization. The inhomogeneity generated by torsional shear deformation in bulk metallic glasses can be detected in internal surfaces. The final structure and morphology of the deformed material depend on the processing parameters (deformation rate, shear strain, temperature and pressure) of the high-pressure torsion apparatus. [doi:10.2320/matertrans.MF201917]

(Received February 1, 2019; Accepted April 11, 2019; Published June 25, 2019)

Keywords: bulk metallic glass, high-pressure torsion, amorphous, severe plastic deformation, glass forming ability

\section{Introduction}

Bulk metallic glasses (BMGs) lacking long range atomic order and extended structural faults such as dislocations and grain boundaries, ${ }^{1-4)}$ have been achieving increasing attention in the last couple of decades due to their outstanding mechanical properties, ${ }^{5-7)}$ however, their applications are strongly limited because of expensive components, requirement of careful preparation conditions and low ductility. ${ }^{1,8)}$ Plastic deformation of BMGs can occur in two different ways. At low temperature, usually below the glass transition temperature $\left(\mathrm{T}_{\mathrm{g}}\right)$ inhomogeneous deformation takes place at high stresses with the nucleation and propagation of sharp shear bands before brittle fracture. ${ }^{8-11)}$ These shear bands are very thin $(\sim 10 \mathrm{~nm})$ and characterized by remarkably enhanced atomic mobility and occasionally local temperature rise. ${ }^{12,13)}$ Spatial inhomogeneity often affects the mechanical properties of these materials. ${ }^{14,15)}$ As the applied temperature approaches $T_{g}$, the localized deformation shows a transition to homogenous mode throughout the entire volume of the specimen. ${ }^{2,3)}$ The deformation behavior strongly depends on the applied strain rate: at lower strain rates the flow is Newtonian, whilst at high rates BMGs obey a nonNewtonian behavior. ${ }^{16)}$ In this regime the viscosity of the glass drops by several order of magnitude. ${ }^{17,18)}$ The mechanical properties, especially the ductility of BMGs can be improved by dispersing the macroscopic deformation among large number of competitive shear bands either by introducing structural or compositional inhomogeneity into the microstructure ${ }^{19,20)}$ or by surface constrains techniques, ${ }^{21,22)}$ e.g. by high pressure torsion (HPT). ${ }^{23-28)}$

Among the large variety of the different severe plastic deformation (SPD) techniques, HPT has been devoted a focused attention in the last decades due to the very high applied shear strain in a practically large sample volume. ${ }^{29)}$ Probably known only by few, the HPT technique was invented in 1935 by Bridgman, as was highlighted its historical importance by Edalati and Horita. ${ }^{30)}$ During the HPT deformation process, a disk-shape specimen is placed between two stainless steel anvils and subjected to simultaneous compressive force and concurrent torsional straining for several rotations $(\mathrm{N})$ under an applied hydro- static pressure of several GPa. ${ }^{31,32)}$ The accumulated shear strain for torsion deformation can be represented by

$$
\gamma=\frac{2 \pi N r}{L}
$$

where $\mathrm{r}$ an $\mathrm{L}$ are the distance from the rotation axis and the thickness of the disk, respectively. ${ }^{29,31)}$ Eventually, the technique was originally applied to prepare porosity-free bulk ultrafine-grained materials, ${ }^{31-33)}$ recently it has become a powerful technique to produce low-porosity metallic glass compacts from amorphous ribbon pieces ${ }^{24,34)}$ and reach large plastic strains in bulk glassy alloys. ${ }^{35)}$ Since HPT operates in constrained geometry without free surfaces, see the schematic illustration in Fig. 1, ${ }^{36)}$ room temperature plastic deformation can only be estimated on average from sample dimensions and the relative rotation of the anvils. ${ }^{37}$ )

In this overview paper we demonstrate that severe shear deformation in a HPT experiment can promote (partial) amorphization in high glass forming systems (Section 2) and deformation induced crystallization in monolithic metallic glasses (Section 3). In Section 4 several models estimating the temperature conditions in an amorphous HPT-disk are presented and correlated with the observed microstructure. In some cases HPT is applied to BMGs at different external temperatures, the role of the processing parameters is

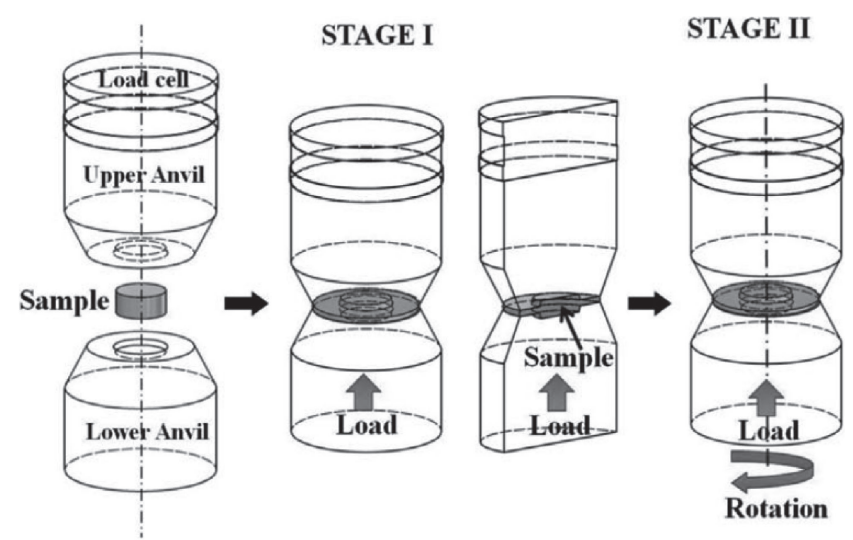

Fig. 1 Schematic illustration of the HPT device with the compression (I) and compression+torsion (II) stages. ${ }^{36}$ ) 
discussed in Section 5. Plastic deformation during HPT induces structural anisotropy in BMGs, as it is highlighted in Section 6 . The inhomogeneity generated by torsional shear deformation in BMGs can be detected in an internal surfaces of a HPT-disk and in free surfaces of cylindrical specimen (Section 7). In the last part of the manuscript (Section 8), outstanding properties, such as induced tensile plasticity and enhanced hydrogen storage performance of the severely deformed BMGs will be summarized.

\section{Amorphization by HPT}

Besides rapid quenching of the melt to solidify the liquid structure $^{38,39)}$ amorphous and partially amorphous systems can be produced via crystalline-to-amorphous transformation of the solid state by SPD. It was shown by high-resolution transmission electron microscopy (TEM) studies that this phase transformation initiates from grain boundaries of the (nano)crystals and the dislocation cores located in the grain interiors. $^{40)}$ Due to variation of the applied strain, the microstructure of a ternary $\mathrm{Cu}_{60} \mathrm{Zr}_{20} \mathrm{Ti}_{20}$ alloy exhibits a strong radial dependence. ${ }^{41)}$ In the vicinity of the torsion axis large blocks of about $50 \mu \mathrm{m}$ are embedded in a matrix, while at larger distances the blocks break up and transform into partially amorphized lamellae. The hardness of the disks shows a remarkable maximum $(5 \mathrm{GPa})$ at around half radius, which then decreases at the perimeter of the disk, in accordance with the refining microstructure. ${ }^{42)}$ The extreme shear deformation generated during the HPT process can promote the formation of some amorphous content in an only two component $\mathrm{Cu}_{64.5} \mathrm{Zr}_{35.5}$ crystalline alloy having an exceptional glass forming ability, as was confirmed by calorimetric and local X-ray diffraction (XRD) measurements. ${ }^{43)}$ During the crystalline-to-amorphous transformation process, no intermetallic phase formation was detected in the $\mathrm{Cu}-\mathrm{Zr}$ system which enables the production of the amorphous phase in a wide composition range. ${ }^{44)}$ It was found that HPT can induce a significant amount of amorphous volume fraction in the bulk glass forming $\mathrm{Zr}$ $\mathrm{Cu}-\mathrm{Al}$ system, i.e. a fully amorphous structure can be obtained from crystalline master alloys after $\mathrm{N}=50$ revolutions. ${ }^{45)}$ The volume fraction of the amorphous structure strongly depends on the HPT processing temperature, i.e. an increase of the external temperature significantly promotes the amorphization. ${ }^{46)} \mathrm{T}_{\mathrm{g}}$ of the alloys produced by the solid state reaction process is very similar to that of the as-quenched counterparts. ${ }^{45)}$ In some particular cases the accumulation of deformation yields not only the crystallineto-amorphous transformation, nonetheless a cyclic crystalline $\rightarrow$ amorphous $\rightarrow$ crystalline sequence can take place, as was demonstrated for the $\mathrm{Ti}-\mathrm{Ni}-\mathrm{Cu}$ system. ${ }^{47)}$ In a systematic review of Glezer et al. the phenomenon of deformation induced phase transformation from crystalline compounds to single phase amorphous state and vice versa have been analyzed in the frame of non-equilibrium thermodynamics. ${ }^{48)}$

Starting from $\mathrm{Zr}-\mathrm{Cz}-\mathrm{Al}-\mathrm{Ni}-\mathrm{Ti}$ amorphous metallic glass powders and crystalline $\mathrm{Cu}$, it was shown that the refinement of the microstructure can be tuned by varying the applied shear strain during the HPT procedure. Namely, rotations up to $\mathrm{N}=500$ provide sufficient deformation to obtain a single phase massive bulk amorphous piece with enhanced mechanical behavior. ${ }^{49)}$ In some cases the crystalline component can be replaced by a second glassy powder, as was recently reported by Pippan and coworkers. ${ }^{50)}$ In their work, gasatomized Zr-based and Ni-based glassy powders were mixed together and subjected to HPT. At the highest applied strain a transition to a single phase state can be obtained, which illustrates the potential to produce novel BMGs by deformation induced mixing. ${ }^{50)}$

\section{Deformation Induced Crystallization in Amorphous Alloys by HPT}

Typically, metallic glasses can be produced in a wide composition range by fast cooling in good glass former alloy families. On contrary, BMGs require orders of magnitude lower cooling rate to avoid crystallization and therefore they can be cast only at specific compositions. ${ }^{51)}$ To extend the available compositions for BMG production, low temperature severe shear deformation compaction methods, such as HPT, were successfully applied for rapidly quenched Al-RE$\mathrm{TM},{ }^{52)} \mathrm{Cu}-\mathrm{Zr}^{53)}$ and $\mathrm{Mg}-\mathrm{Cu}-\mathrm{RE}^{54)}$ alloys. These systems crystallize easily via various devitrification routes on different external impacts. In the following, we will discuss these devitrification routes in detail for different Al-RE-TM alloys.

\subsection{Severe plastic deformation of Al-based metallic glasses}

Due to their low density, Al-based alloys are widely used in structural applications, however, their yield strength cannot be increased over $500-600 \mathrm{MPa}$ in crystalline structures. ${ }^{51,55)}$ In the late 1980s, rapidly quenched Al-based alloys with non-periodic atomic structure have been discovered possessing a yield strength close to $1 \mathrm{GPa}^{56-58)}$ Since these metallic glass alloys can only be produced in ribbon form due to the required high cooling rate to avoid crystallization, HPT was applied to obtain pore free bulk pieces from 20-100 micrometer thin ribbon flakes ${ }^{59)}$ (see Fig. 2). As a side effect of SPD, Al-based metallic glasses exhibit partial devitrification into metastable states which also consist of

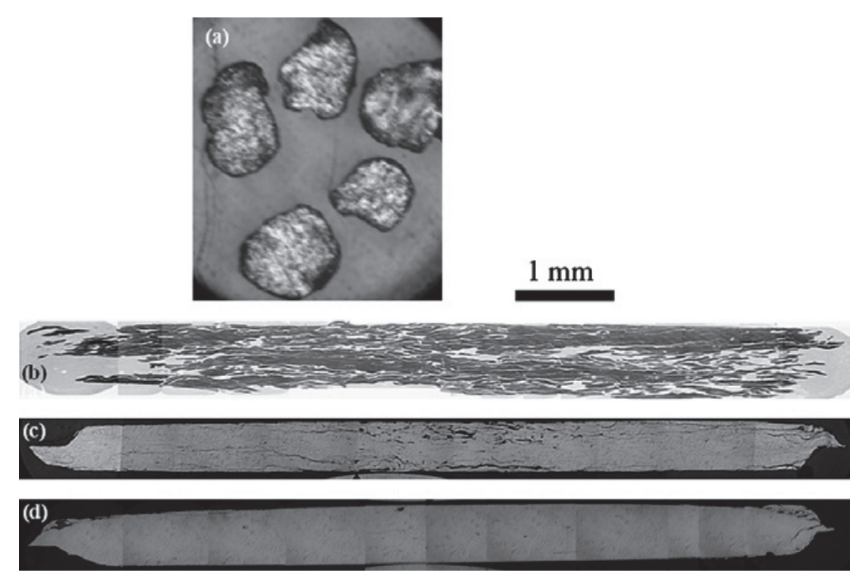

Fig. 2 Optical micrographs of the $\mathrm{Al}_{85} \mathrm{Ce}_{8} \mathrm{Ni}_{5} \mathrm{Co}_{2}$ metallic glass material at different stages of the compaction process. (a) Plane view of flake particles and the cross-sectional view of (b) pre-compacted, (c) HPT $\mathrm{N}=1$ and (d) HPT $\mathrm{N}=5$ disks. The scale bar corresponds to all of the images. ${ }^{59)}$ 


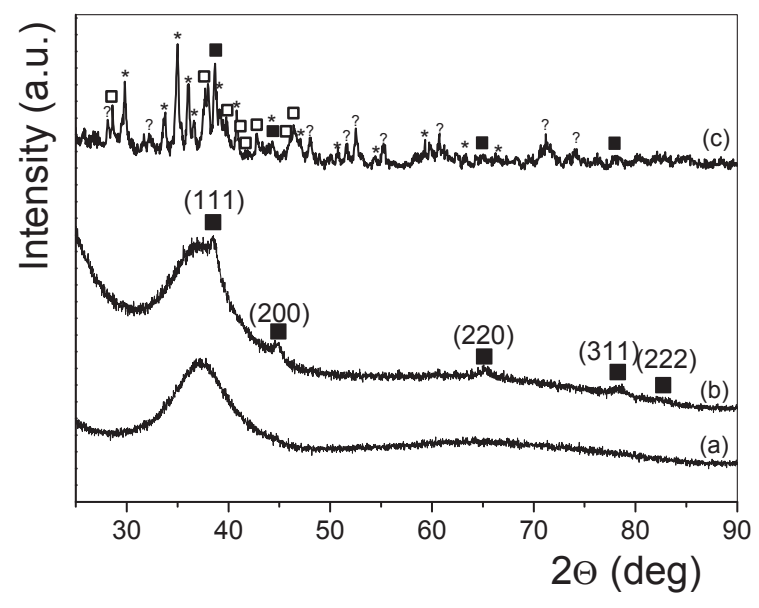

Fig. 3 XRD patterns of the as-quenched (a) and plastically deformed (b) $\mathrm{Al}_{85} \mathrm{Ce}_{8} \mathrm{Ni}_{5} \mathrm{Co}_{2}$ alloy. The linear heating of the as-quenched ribbon up to $592 \mathrm{~K}$ results in the formation of several crystalline phases (c). The symbols $\square, \square, *$ and ? denote the Bragg-peaks of $\alpha$-Al, orthorhombic $\mathrm{Al}_{3} \mathrm{Ni}$, orthorhombic $\mathrm{Al}_{11} \mathrm{Ce}_{3}$ and unknown phase(s), respectively. ${ }^{52)}$

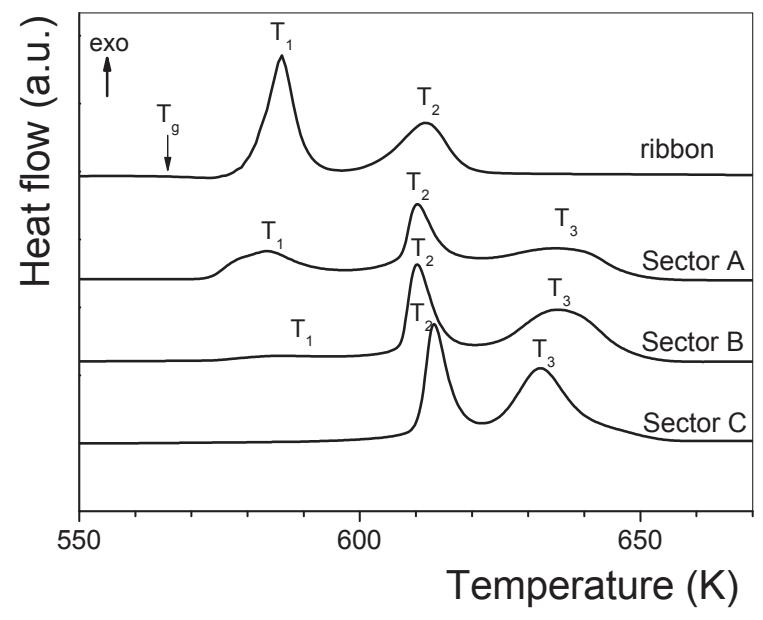

Fig. 4 DSC curves of the as-quenched $\mathrm{Al}_{85} \mathrm{Ce}_{8} \mathrm{Ni}_{5} \mathrm{Co}_{2}$ ribbon and different sectors of the HPT disk obtained at $40 \mathrm{~K} \mathrm{~min}^{-1}$ heating rate. The glass transition $\left(T_{\mathrm{g}}\right)$, and the main exothermic peaks $\left(\mathrm{T}_{1}, \mathrm{~T}_{2}\right.$ and $\left.\mathrm{T}_{3}\right)$ are also indicated. ${ }^{52)}$

crystalline phases different from the equilibrium phase mixture of the corresponding alloy. While, thermal treatment of the as-quenched $\mathrm{Al}_{85} \mathrm{Ce}_{8} \mathrm{Ni}_{5} \mathrm{Co}_{2}$ ribbon results in the joint formation of several crystalline phases, plastic deformation at room temperature induces only primary precipitation of fccAl nanocrystals ${ }^{52,60)}$ (see Figs. 3 and 4). Nevertheless, minor decrease in the rate of the deformation procedure leads to change in the devitrification product and results in a mixture of sparsely distributed $\mathrm{Al}_{11} \mathrm{Ce}_{3}$ crystalline blocks and $\mathrm{Al}$ nanocrystals. ${ }^{61)}$ On the other hand, both thermal treatment and HPT deformation results in the nucleation of the primary fcc-Al phase in fully amorphous $\mathrm{Al}_{85} \mathrm{Y}_{8} \mathrm{Ni}_{5} \mathrm{Co}_{2}$ alloy. ${ }^{62)}$ In HPT, no detectable crystalline product was observed up to high shear strain (Fig. 5), however, subsequent thermal investigations reflects significant structural changes, i.e. different thermal stability and different degree of ordering in the residual matrix, even at lower strain. ${ }^{62}$ )

In amorphous $\mathrm{Al}_{85} \mathrm{Gd}_{8} \mathrm{Ni}_{5} \mathrm{Co}_{2}$ alloy, which exhibits primary crystallization of the fcc $\mathrm{Al}$ phase above $560 \mathrm{~K}$ and

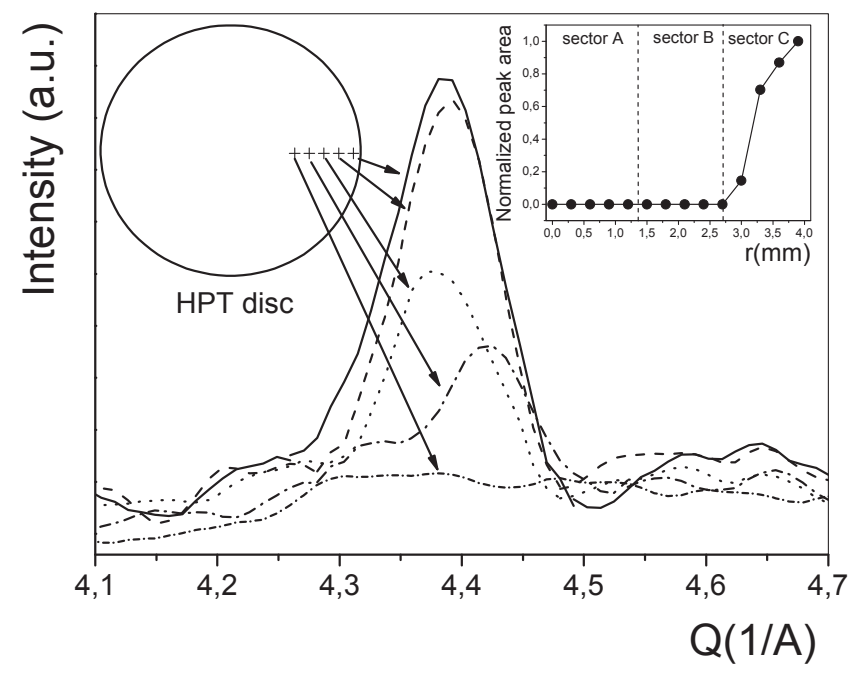

Fig. 5 XRD patterns of the $\left\{\begin{array}{lll}2 & 2 & 0\end{array}\right\}$ fcc-Al Bragg-peak recorded along a diameter of the $\mathrm{Al}_{85} \mathrm{Y}_{8} \mathrm{Ni}_{5} \mathrm{Co}_{2}$ HPT disk as indicated schematically. The inset shows the integrated intensity of the $\left\{\begin{array}{lll}2 & 2 & 0\end{array}\right\}$ fcc-Al Bragg-peak as a function of the distance from the center of the disk. ${ }^{62)}$

a mixture of fcc-Al and a metastable phases below $560 \mathrm{~K}$, SPD by high-pressure torsion results in partial devitrification into a dual microstructure containing nanocrystals $(\sim 5 \mathrm{~nm})$ and blocks $(\sim 50 \mathrm{~mm})$ of the crystalline mixture. The largest blocks initiate in the early stage of the HPT when the deformation is inherently inhomogeneous and the average temperature is well below $\mathrm{Tg}$. On the other hand, the smallest crystals grow homogeneously, which is reminiscent to the microstructure obtained by heat treatments in the supercooled liquid state. ${ }^{63)}$

Detailed thermal and structural study on isothermal heat treatment, high pressure torsion and ball milling revealed several different devitrification routes for amorphous $\mathrm{Al}_{85} \mathrm{Ce}_{8} \mathrm{Ni}_{5} \mathrm{Co}_{2}$ alloy depending on the process and the processing parameters. ${ }^{64,65)}$ Devitrification routes of the HPT process shows similarities to that of low temperature heat treatments near the glass transition temperature, possessing limited mobility for crystal nucleation. ${ }^{65)}$ In nucleation theory, the pressure (p) modified nucleation activation energy barrier can be expressed as

$$
\Delta G(T, p)=\frac{16 \pi \sigma^{3}}{3}\left(\frac{V_{m}^{c}}{\Delta G_{m}+p \Delta V}\right)^{2},
$$

where the $\Delta \mathrm{G}_{\mathrm{m}}$ and $\sigma$ are molar free energy difference and the interfacial free energy between the amorphous and crystalline phases, respectively. As an effect of the applied pressure in HPT, the $\Delta \mathrm{G}$ nucleation barrier of dense crystalline phases can decrease significantly due to the $\Delta \mathrm{V}$ difference in molar volume $\left(V_{m}^{c}\right)$ of the nucleating phases.

\section{Temperature Rise in BMGs during HPT}

Until now very little information is available on the temperature rise that occurs in the amorphous glassy alloys during the HPT straining procedure. In order to estimate the temperature generated by extensive shear deformation of bulk metallic glasses, a macroscopic quasi three-dimensional thermoplastic model based on heat conduction has been 


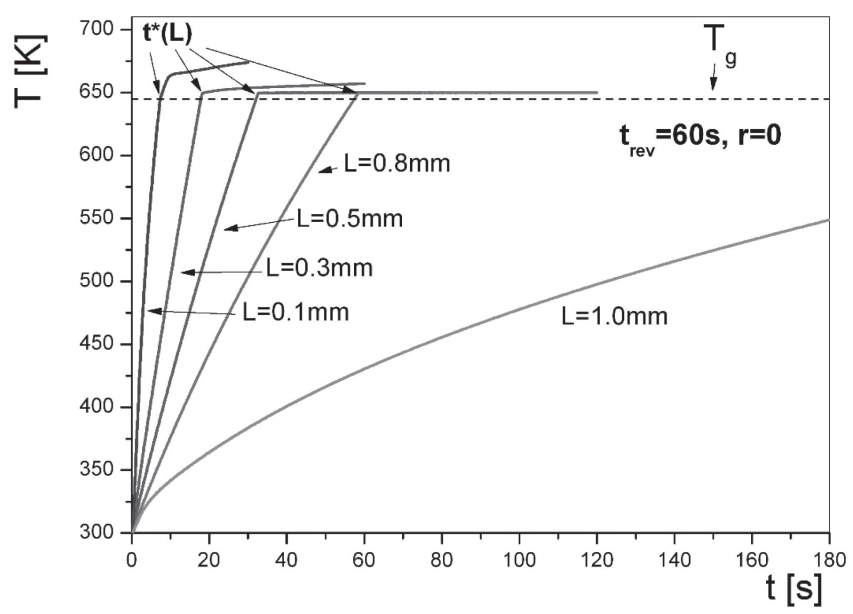

Fig. 6 Temperature evolution as a function of the processing time at $\mathrm{r}=0$, for different $\mathrm{L}$ values with $\mathrm{t}_{\mathrm{rev}}=60 \mathrm{~s}^{66)}$

constructed. ${ }^{66)}$ As it is confirmed by a series of calculated temperature curves with the same revolution time $\left(\mathrm{t}_{\mathrm{rev}}=60 \mathrm{~s}\right)$ but different disk thickness $(\mathrm{L}=0.1 \mathrm{~mm}-1.0 \mathrm{~mm})$, the temperature can exceed the glass transition, see Fig. 6. Here $t^{*}$ denotes the characteristic time to reach the glass transition for different sample thicknesses. Once $\mathrm{T}_{\mathrm{g}}$ is reached, the slope of the temperature profiles decreases rapidly, which corresponds to a drastic decrease of mechanical energy input. ${ }^{67)}$ It is apparent that the temperature of the thickest sample $(\mathrm{L}=1.0 \mathrm{~mm})$ does not reach $\mathrm{T}_{\mathrm{g}}$ during reasonably long processing time. Fairly different behavior corresponds to longer revolution times, i.e. the rate of temperature rise is considerably lower, in conjunction with only a moderate increase saturated well below $\mathrm{T}_{\mathrm{g}}$.

Depending on the deformation and geometrical parameters, the temperature can either exceed $\mathrm{T}_{\mathrm{g}}$ at $\mathrm{t}^{*}$ followed by a subsequent homogeneous deformation, or remain lower corresponding to localized deformation during the entire process, as it is summarized in a parameter map in Fig. 7. The measured temperature increase for a $\mathrm{CuZr}(\mathrm{Al})$ metallic glass is in good accordance with the calculated values. ${ }^{44)}$ Since important structural changes in BMGs occur at $\mathrm{T}_{\mathrm{g}}$, the HPT-process can result in different microstructure. Recent

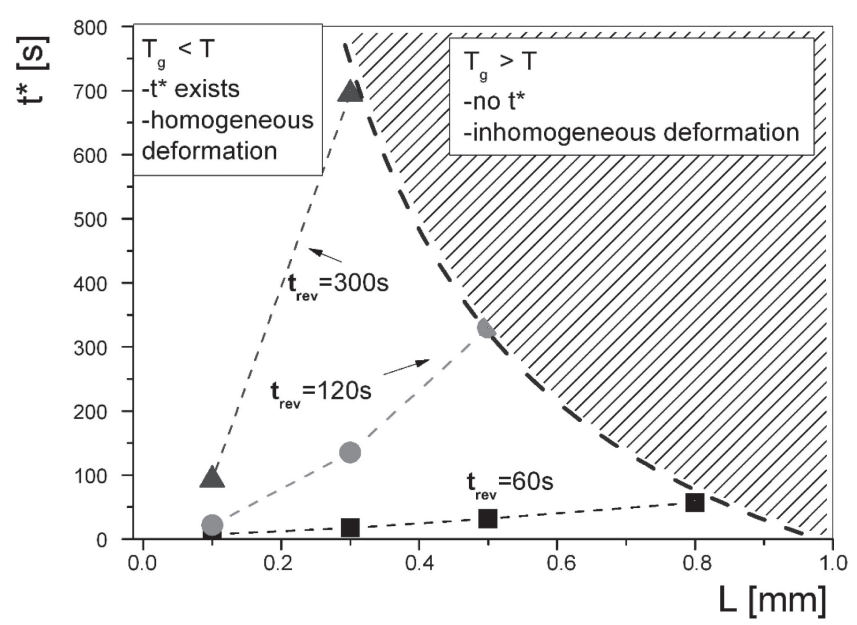

Fig. 7 Characteristic time $t^{*}$ for reaching $T_{g}$ as a function of the sample thickness $L$ for different $t_{\text {rev }}$ revolution times. In the upper right region of the plot $\mathrm{t}^{*}$ does not exist indicating that temperature remains below $\mathrm{T}_{\mathrm{g}}{ }^{66 \text { ) }}$ experiments on amorphous BMGs deformed by HPT are in agreement with the results of this model. For example, applying severe torsion with smaller angular velocity preserves the fully amorphous nature of $\mathrm{Zr}_{57} \mathrm{Ti}_{5} \mathrm{Cu}_{20} \mathrm{Al}_{10} \mathrm{Ni}_{8}$ $\mathrm{BMG},{ }^{68)}$ see also Chapter 6. On the other hand, partial crystallization occurs in a $\mathrm{Cu}_{60} \mathrm{Zr}_{30} \mathrm{Ti}_{10}$ metallic glass when the torsion was conducted at $t_{\mathrm{rev}}=60 \mathrm{~s}$, ${ }^{67,69)}$ however, due to the radial dependent shear deformation, the disk exhibits gradient microstructure, i.e. the interior is characterized by large deformed crystalline blocks, while the perimeter is abundant in homogeneously dispersed nanocrystals embedded in the amorphous matrix. The observed microstructural and morphological changes are the consequences of low viscosity during the high temperature annealings $\left(\sim \mathrm{T}_{\mathrm{g}}\right)$ and the simultaneous shear deformation. When $\mathrm{t}_{\text {rev }}=60 \mathrm{~s}$ is applied to a $\mathrm{Zr}_{55} \mathrm{Cu}_{30} \mathrm{Al}_{10} \mathrm{Ni}_{5} \mathrm{BMG}$, high resolution TEM equipped with a corrector for astigmatism reveals the formation of two face-centered cubic clusters/ nanocrystals with different lattice parameters, see Fig. 8. ${ }^{70)}$ The first type most likely corresponds to (pure) $\mathrm{Cu}$-clusters, which might indicate that the observed structural changes are similar to those occurred at low temperature annealing. The second type of cluster has a lattice parameter of 55.2 Á.
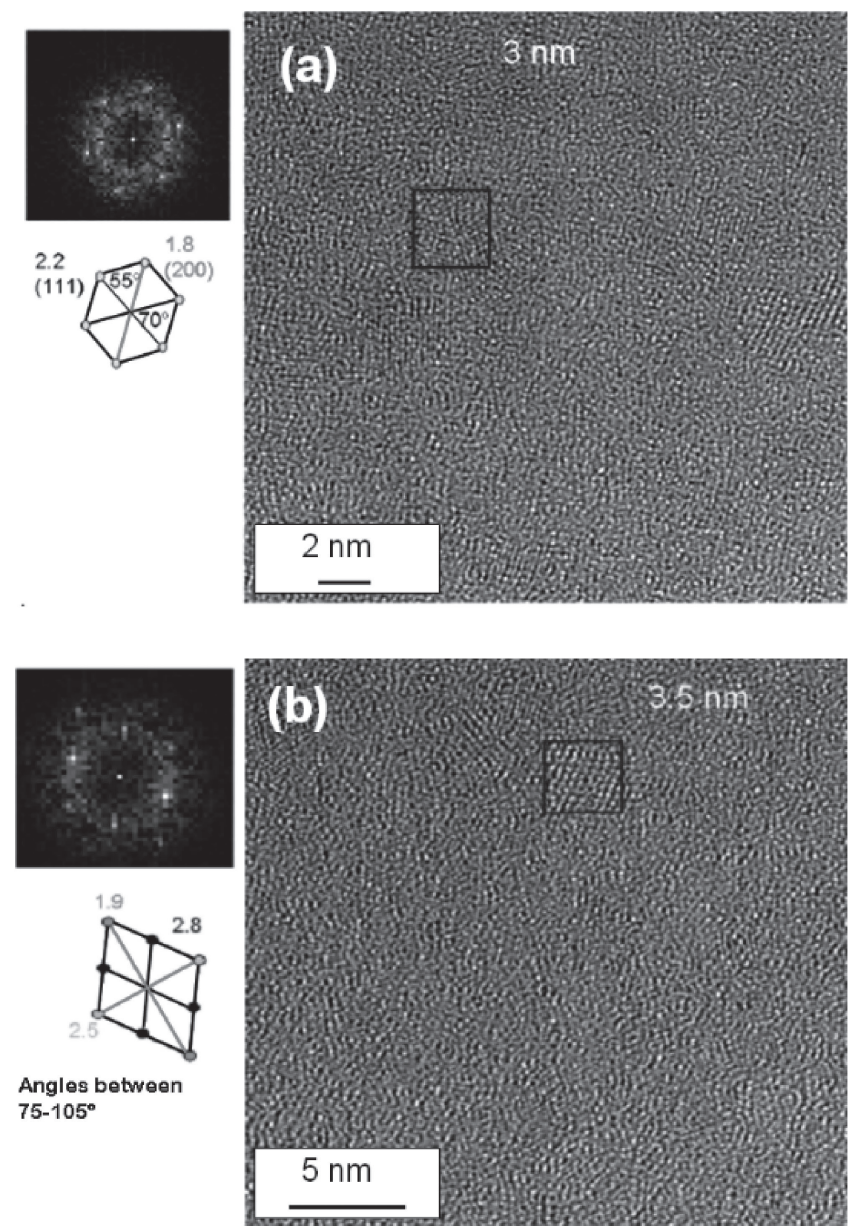

Fig. 8 Analysis of the clusters/nanocrystals in a $\mathrm{Zr}_{55} \mathrm{Cu}_{30} \mathrm{Al}_{10} \mathrm{Ni}_{5}$ glass deformed by high pressure torsion by high-resolution transmission electron microscopy with a $\mathrm{C}_{\mathrm{s}}$ corrector. Two main clusters have been analyzed: (a) pure $\mathrm{Cu}$-clusters and (b) an fcc-type cluster with lattice parameter around 5-5.2 Á. ${ }^{70)}$ 


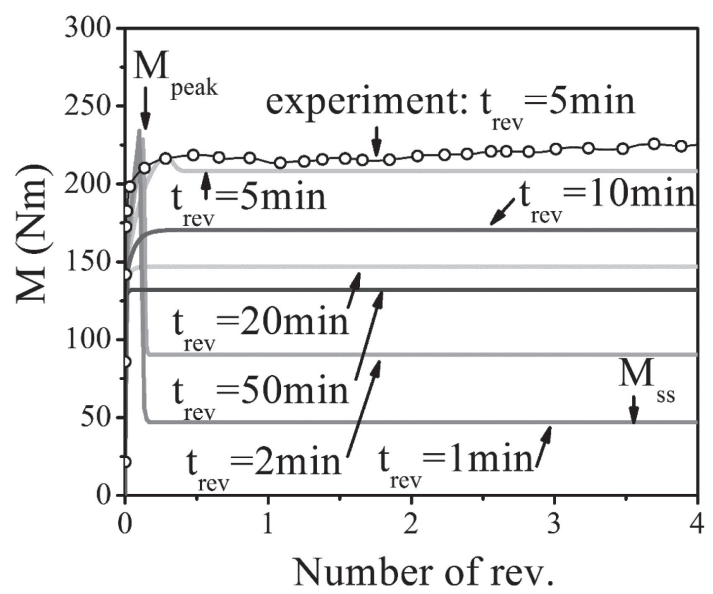

Fig. 9 Simulated torque evolution curves, $M(t)$, for different HPT revolutions periods $\left(\mathrm{t}_{\mathrm{rev}}=1,2,5,10,20\right.$ and $\left.50 \mathrm{~min}\right)$ and a measured $\mathrm{M}(\mathrm{t})$ curve for $\mathrm{t}_{\text {rev }}=5$ min. $\left.{ }^{75}\right)$

Based on finite element modelling, Figueiredo et al. evaluated the thermal behavior and temperature increase during HPT-processing. ${ }^{71}$ ) The temperature evolution in the HPT-disk follows similar general trends under constrained, quasi-constrained and unconstrained geometries. ${ }^{72)}$ It was also shown by a constructed normalized master curve that the temperature rise is proportional to the angular velocity of the apparatus, ${ }^{71,73)}$ however, the increase is less significant for crystalline materials ${ }^{71,74}$ ) than for amorphous systems. ${ }^{66}$ ) Because of the robust construct of HPT apparatus, in-situ investigations are very difficult during the procedure. Torque (M) is one of the process parameter that can be measured easily in-situ. As seen in Fig. 9, simulated M(t) curves corresponding to different $t_{\text {rev }}$ revolution times approach an $\mathrm{M}_{\mathrm{ss}}$ steady state value. ${ }^{75)}$ For faster HPT experiments $\left(\mathrm{t}_{\mathrm{rev}}=\right.$ $1 \mathrm{~min}, 2 \mathrm{~min}$ and $5 \mathrm{~min}$ ) peak $\left(\mathrm{M}_{\text {peak }}\right)$ on the $\mathrm{M}(\mathrm{t})$ curves can also be observed, indicating that $T_{g}$ has been reached during these deformation strainings. For comparison, an experimentally recorded $\mathrm{M}(\mathrm{t})$ curve obtained with $\mathrm{t}_{\mathrm{rev}}=$ 5 min obeys a qualitative agreement with the results of the simulations. ${ }^{76)}$ Applying longer periodic times $\left(\mathrm{t}_{\mathrm{rev}}=10 \mathrm{~min}\right.$, $20 \mathrm{~min}$ and $50 \mathrm{~min}$ ), the $\mathrm{M}(\mathrm{t})$ curves monotonously converge to $\mathrm{M}_{\mathrm{ss}}$ beyond the yield point, indicating that the temperature remains below $\mathrm{T}_{\mathrm{g}}$ during the whole HPT process.

Based on the solution of the quasi three-dimensional heat conduction model, the temperature remains below $\mathrm{T}_{\mathrm{g}}$ for slower rotations $\left(t_{\text {rev }}=120 \mathrm{~s}\right.$ and $\left.t_{\text {rev }}=180 \mathrm{~s}\right)$ during an entire process of $\mathrm{N}=5$ whole revolutions for $\mathrm{Cu}-\mathrm{Zr}-\mathrm{Ti}$ metallic glasses, indicating that the extreme deformation promotes the formation of narrow shear bands. ${ }^{77)}$ At the same time, the corresponding XRD pattern indicates that the alloy is almost fully amorphous, ${ }^{78}$ ) however fine nanocrystal may nucleate from the amorphous matrix in the vicinity of the locally heated deformation zones. ${ }^{69)}$ For low shear rate, the observed morphology is independent of the deformation (i.e. the distance from the torsion axis). ${ }^{78)}$ When the $\mathrm{Cu}$-based metallic glass is deformed by higher shear rate $\left(t_{\mathrm{rev}}=60 \mathrm{~s}\right)$ the temperature reaches $T_{g}$ in a relatively short time, results in the intensive formation of hcp $\mathrm{Cu}_{51} \mathrm{Zr}_{14}$ and hep $\mathrm{Cu}_{2} \mathrm{ZrTi}$ phases even at the centre of the disk. ${ }^{78)}$ Nevertheless, as the temperature exceeds $T_{g}$, the further growth and coalescence of these nanocrystals are strongly limited by the persistent shear in the perimeter, resulting in a deformation dependent microstructure and morphology. ${ }^{53,78)}$ When a $\mathrm{Cu}_{60} \mathrm{Zr}_{30} \mathrm{Ti}_{10}$ metallic glass was subjected to different amount of rotational straining at a fixed deformation rate $\left(\mathrm{t}_{\mathrm{rev}}=60 \mathrm{~s}\right)$, it was found that the center of the $\mathrm{N}=5$ HPT disk is abundant in elongated blocks which transforms into more robust, eutecticlike morphology after further deformation $(\mathrm{N}=10)$. It was obtained from synchrotron X-ray diffraction that these blocks contain (nano)crystallites. ${ }^{79)}$ The remarkable different microstructure developed across the diameter of the disks can be explained by the competition of local strain rate and thermal mobility. In a comparative study of Asgharzadeh et al., CuZrTi metallic glass powder was compacted by HPT until different ultimate strains and they found that the consolidated disks exhibit high relative density at larger rotation numbers $(\mathrm{N}=5)$ without detectable devitrification. ${ }^{80)}$

\section{The Role of External Processing Temperature}

High-pressure torsion carried out at different external temperatures can serve as a chance to tune the inherent properties of bulk metallic glasses to achieve notable thermal stability and desirable mechanical properties for specific applications. It was shown very recently that a Vitreloy $\mathrm{Zr}_{44} \mathrm{Ti}_{11} \mathrm{Cu}_{10} \mathrm{Ni}_{10} \mathrm{Be}_{25}$ bulk metallic preserves the the monolithic amorphous nature of the alloy up to processing temperatures reaching $\mathrm{T}_{\mathrm{g}}(\sim 620 \mathrm{~K})$, however, destabilization takes place at $630 \mathrm{~K}$, when the nucleation of a metastable quasicrystalline phase (QC) and $\mathrm{Zr}_{2} \mathrm{Cu}$ occurs, as seen in Fig. 10. ${ }^{81)}$ At the same time, HPT performed at $630 \mathrm{~K}$ results in a remarkable decrease in the thermal stability, while a pure isothermal annealing at similar temperature seemingly preserves the amorphicity and thermal behavior of the as-cast glass. An amorphous-nano(quasi)crystalline composite structure has also been attained by a simple linear heating experiment up to $690 \mathrm{~K} .{ }^{81)}$ Depth sensing hardness measure-

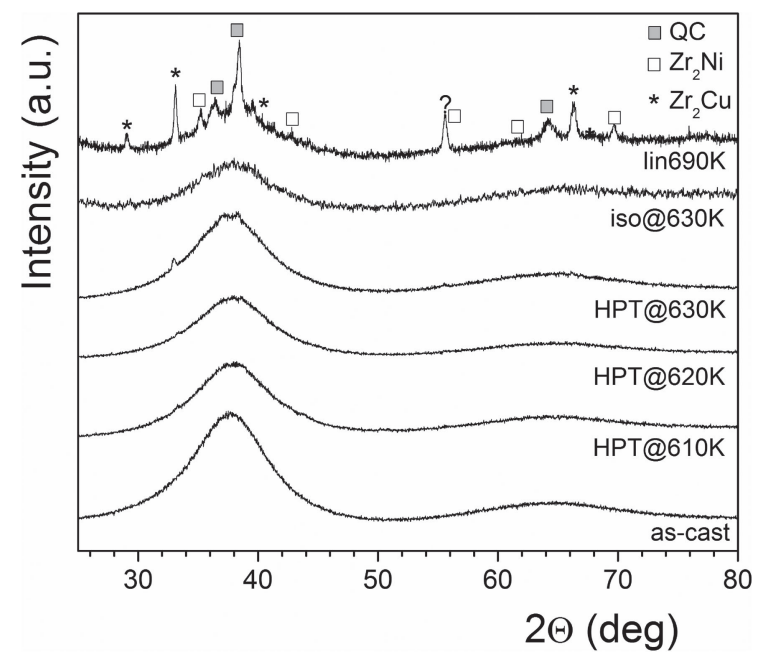

Fig. $10 \mathrm{XRD}$ patterns of the as-cast Vitreloy $\mathrm{Zr}_{44} \mathrm{Ti}_{11} \mathrm{Cu}_{10} \mathrm{Ni}_{10} \mathrm{Be}_{25}$ bulk metallic glass and different samples deformed by high temperature HPT method. For comparison, the XRD pattern of the relaxed state (iso@630K) and the thermally devitrified state which was obtained by linear heating above the first crystallization peak to $690 \mathrm{~K}$, are also depicted. ${ }^{81)}$ 
ments confirms a significant hardening on the HPT-disk obtained at $630 \mathrm{~K}$ which can directly be correlated with the change of the nanostructure of the glass and the appearance of the QC phase. ${ }^{81)}$ Remarkable changes in the structural properties, mechanical and thermal behavior were obtained by Eckert and coworkers on a $\mathrm{Zr}_{55} \mathrm{Cu}_{30} \mathrm{Al}_{10} \mathrm{Ni}_{5}$ bulk metallic glass processed by HPT at temperatures close to the glass transition. ${ }^{82}$ They found that variation of the processing temperature results in structural changes, i.e. the reconfiguration of the $\mathrm{Zr}-\mathrm{Zr}$ and $\mathrm{Zr}-\mathrm{Cu}$ atomic pairs. The obtained difference in the thermal behavior at different processing temperatures can be related to the competition between structural relaxation and free volume generation. ${ }^{82)} \mathrm{A}$ significant change in the local atomic environments can also take place when HPT is applied at cryogenic temperature $(77 \mathrm{~K})$, i.e. an increase of $\mathrm{Fe}$ and $\mathrm{B}$ atoms on the first coordination shell of $\mathrm{Fe}$ in a $\mathrm{Fe}-\mathrm{Ni}-\mathrm{B}$ metallic glass. ${ }^{83)}$ This low temperature shear deformation leads to a more nonequilibrium amorphous state in which the short-range order is almost completely missing. If a gas-atomized $\mathrm{Cu}$-based metallic glass is subjected to HPT at elevated temperatures, the densification and drawability of the material increase. The coupled rise in the crystallization enthalpy with increasing processing temperature suggests that a net free volume generation takes place. ${ }^{80)}$ Structural characterization of meltspun $\mathrm{Ti}-\mathrm{Ni}-\mathrm{Cu}$ amorphous ribbons compacted by HPT for $\mathrm{N}=10$ whole rotations at $423 \mathrm{~K}$ revealed the formation of amorphous nanoclusters which are separated by amorphous boundaries of different topology. ${ }^{84)}$ The size of these clusters are altered by the HPT processing temperature. ${ }^{85}$ The obtained less homogeneous microstructure leads to a broader crystallization event. ${ }^{84}$ ) The change in fracture surface from vein-like pattern of the as-quenched alloy to a "small-dimple" structure of the HPT-disk corresponds to a more ductile state.

\section{Structural Changes in Metallic Glasses during HPT}

Generally, plastic deformation induces structural anisotropy in metallic glasses, which was demonstrated by Suzuki et al. using energy dispersive X-ray diffraction in creep experiment. ${ }^{86)}$ By the advent of high brilliance and high stability monochrome synchrotron X-ray radiation, the small distortions (order of $10^{-2}-10^{-3}$ ) of the amorphous diffraction halo became directly measurable. ${ }^{87)}$ In such an experiment, typically, two dimensional diffraction patterns are recorded in transmission mode (see the inset of Fig. 11(a)) and distortions of the halos are analyzed directly (Figs. 11(a) and 11(b)) or shifts of the peak positions of the reduced pair distribution function are compared to a reference state. Accordingly, Ott et al. ${ }^{88)}$ measured strain dependent structural anisotropy and excess free volume increase in homogeneous creep deformation (for $<80 \%$ reduction of area) near the glass transition temperature. In creep experiments around the $T_{g}$, the induced anisotropy is due to anelastic behavior and the related cluster rearrangement by bond reformation. ${ }^{86,89)}$

As was aforementioned, deformation become inhomogeneous in BMGs and the plastic deformation localizes in shear bands at lower temperatures. Although, anelasticity is not anticipated in this temperature range, difference was found in
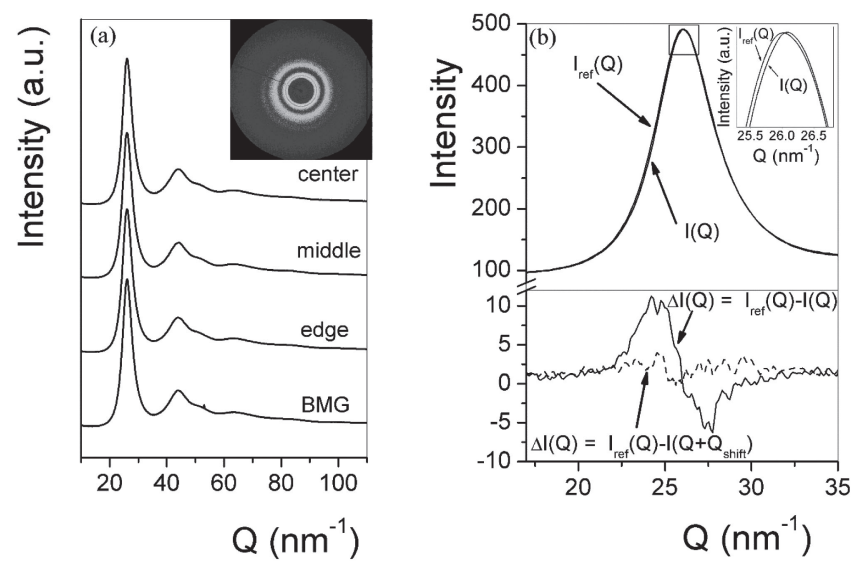

Fig. 11 (a) Integrated diffraction patterns corresponding to different positions on the sample surface of the HPT disk and to the as-cast BMG alloy. The inset shows a typical image recorded by the CCD camera exhibiting only broad diffuse scattering features, which is consistent with a fully amorphous structure. (b) First halo of the reference and a selected position in the HPT disk and the intensity difference plots. ${ }^{68)}$

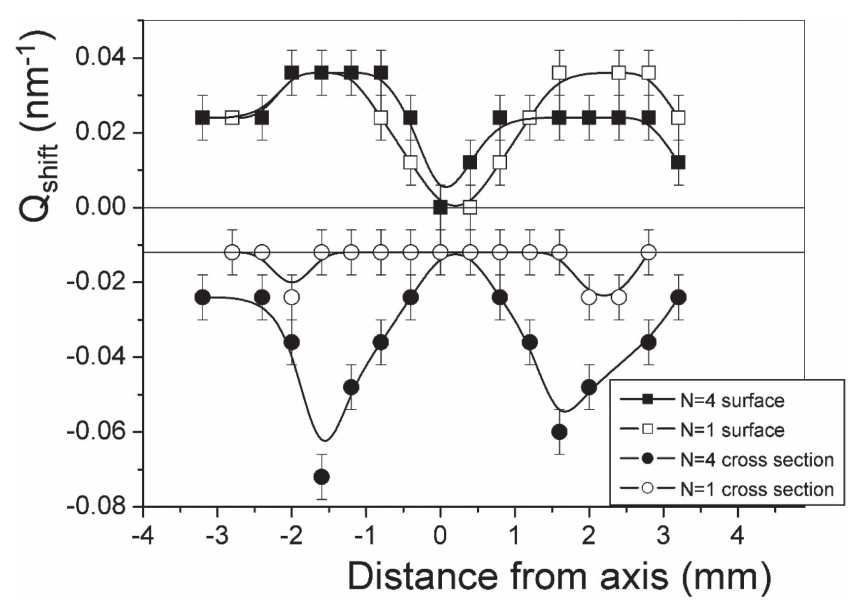

Fig. 12 Shift of the halo positions $\left(\mathrm{Q}_{\text {shift }}\right)$ for $\mathrm{N}=1$ and $\mathrm{N}=4$ torsion numbers along the diameter on the surface and along the cross section of the HPT disks. ${ }^{68)}$

the first integrated halo positions between diffractions captured in the radial and axial directions of HPT disks ${ }^{68}$ ) (see Fig. 12). This indicates that anisotropy can be generated even at room temperature by severe shear deformation. ${ }^{68)}$ Interestingly, shift of the satellite halo position were found to depend linearly in HPT deformed Vitreloylb BMG on the magnitude of the diffraction vector ${ }^{76}$ (Fig. 13). Similarly, Dmowski and Egami also obtained anisotropy in a $\mathrm{Zr}_{50} \mathrm{Cu}_{40} \mathrm{Al}_{10}$ BMG alloy compressed at room temperature and it compared to the anisotropic behavior of a crept metallic glass. ${ }^{89)}$ In a subsequent detailed analysis, Dmowski et al. found that the changes due to HPT deformation in the pair distribution function were opposite to the changes observed for structural relaxation indicating significant increase of the fictive temperature of the glass. ${ }^{90}$ For inhomogeneous deformation, the detected anisotropy of the glass can originate from two sources. One is the real structural anisotropy of the glass, the second is the residual stress which can be produced by the inhomogeneous deformation. Specific residual stress states can induce change in the hardness. In accordance, a drop of the hardness was 


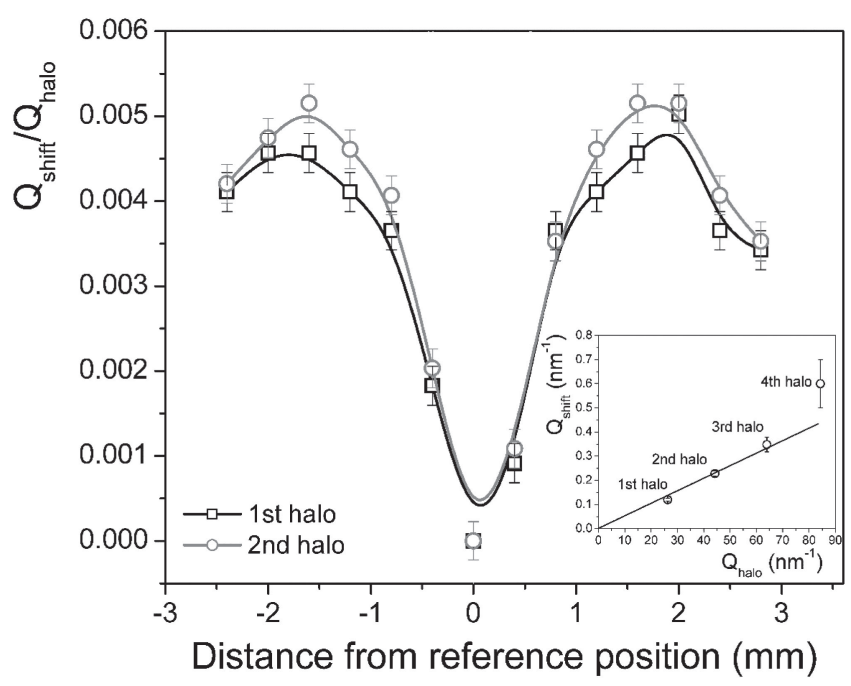

Fig. 13 Variation of the relative halo position shifts for the first and second halos. The inset shows the position dependence of the shift of the first four halos. ${ }^{76)}$

observed near the torsion axis due to the HPT deformation induced structural changes in a $\mathrm{Zr}$-based BMG. ${ }^{91)}$ In a recent work, Adachi et al. demonstrated in $\mathrm{ZrCuAl} \mathrm{BMG}$ that a hardness decrease is due to the built up residual tensile stress $^{92)}$ which decrease the apparent hardness of the indented material.

\section{Inhomogeneity Generated by Shear Deformation in BMGs}

Inhomogeneous deformation takes place in metallic glasses below the glass transition temperature due to the formation of shear bands. ${ }^{6}$ In the following, this inhomogeneity is revealed for HPT deformation and compared to the shear band pattern observed in low pressure free-end torsion tests.

Torsion is a traditional deformation technique which allows to reach severe plastic deformation in various ductile materials at ambient pressure. It has also been applied to plastically deform bulk metallic glass samples, mainly from the Vitreloy $1 \mathrm{~b}$ series. Due to the profound softening in shear banding and the associated instabilities of plastic deformation, the shear strain reached at fracture in torsions scatters between $\gamma=0$ and the order of $\gamma \approx 1 .^{93,94)}$ Advantage of torsional deformation is the relatively simple deformation geometry which initially can be approximated with a radial strain gradient without hydrostatic stress component. Therefore, it can be more directly compared to the results of other low pressure deformation techniques such as uniaxial tests, off axis tests or bending. Evolution of the torque, stress and various acoustic emission parameters in torsion indicates that different stages prevail during plastic straining of BMGs (see Fig. 14). First, followed by the elastic regime the deformation curve is monotonously increasing. This is typical for the microplastic deformation in uniaxial test, while in torsion this stage is more extended due to the stress gradients along the sample radius which control shear bands motion. With increasing deformation, degree of the control is decreases gradually in agreement with the monotonous

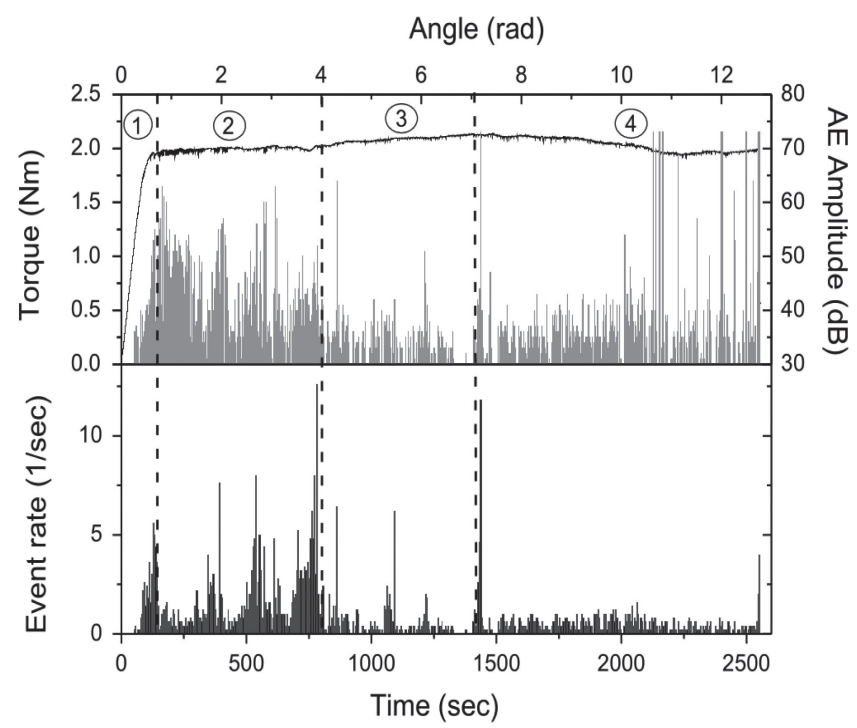

Fig. 14 Changes of the torque, the amplitudes and the event rate of $\mathrm{AE}$ during torsion. The strongly fluctuating amplitude and rate of the acoustic emission events are represented by solid bars. Different deformation stages are indicated by the stage number in circle. ${ }^{94)}$

increase of the acoustic emission amplitude and rate. ${ }^{94)}$ In this initial regime macroscopically no softening or hardening has been observed. ${ }^{93)}$ In the second regime the control of the shear band become negligible. This results in sporadic serrations which exhibits acoustic events with extremely high amplitude. These extreme events are composed of a trail of smaller correlated events with rapidly decreasing time difference. ${ }^{95)}$ With increasing plastic strain at about $\gamma=0.4$, slight strain hardening can be observed in coincidence to the disappearance of serrations and the large acoustic emission events in the subsequent stage. ${ }^{95,96)}$ Finally, gradual softening and very large events indicate the formation of cracks. This stage ends with the fracture of the sample. ${ }^{94,95)}$ Presumably, the transitions between the subsequent stages are induced by the varying inhomogeneity and the corresponding internal stress field in the BMGs. Therefore we also anticipate an evolution in in the shear band structure of BMG samples during HPT deformation.

The localized narrow shear bands at ambient temperature can be observed on the free surfaces of the deformed samples in different unconstrained deformation methods, such as in uniaxial tension, compression, bending. Since, HPT is a method without free surfaces, homogeneity of the plastic deformation can only be estimated on average from the relative rotation of the anvils and typically no information is available on the distribution of plastic shear or even the presence of shear bands within the sample. Hafok and Pippan recognized this problem and analyzed the homogeneity of the HPT deformation successfully in a strain hardening Ni disk consists of two parts and having markers on the internal surface. ${ }^{37)}$ We applied first this procedure for BMGs and studied the distribution of plastic shear strain in the HPT deformed BMG disks. ${ }^{97}$ Figure 15(a) shows the optical image of Vitreloy1b BMG disk consists of two parts with focused ion beam marker grid on its polished inner surface (Figs. 15(b) and 15(c)). After HPT deformation, displacement of the focused ion-beam marker lines in an internal 


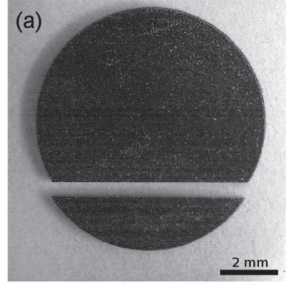

(b)
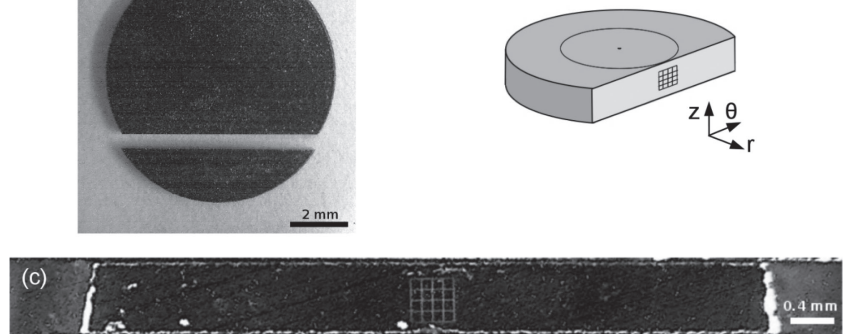

Fig. 15 (a) Optical image of the two parts of an as-cut HPT disk. (b) Schematic view of the larger part of a disk with a focused ion beam milled grid marker imprint on the internal surface. (c) Optical image of the internal surface of a HPT sample with a $0.4 \mathrm{~mm} \times 0.4 \mathrm{~mm}$ FIB milled grid marker. $^{97)}$

surface of the HPT disk showed that the average plastic shear deformation in the interior of the disk scattered from test to test and it was significantly lower than the nominal $\gamma_{\mathrm{pl}}=2.0$ shear strain (the arrows in Fig. 16(a) shows the end points of the sheared marker lines). Rest of the plastic strain localized to either the top or bottom contact surface of the HPT disks.

The measured plastic strain in the interior of the disk distributed homogeneously among the large number of short and wavy shear bands (Fig. 16(a)). The typical shear band distance and shear offset were an order of magnitude smaller than the average band distance and shear offset in the pressure free and open surface torsion tests with comparable average plastic strain, respectively (cf. the shear pattern in Fig. 16(b) and the shear pattern of the same material after free end torsion up to a comparable $\left(\gamma_{\mathrm{pl}}=0.03\right)$ and a larger $\left(\gamma_{\mathrm{pl}}=0.92\right)$ shear strain in Figs. 16(c) and 16(d), respectively). The apparent difference in the shear band distribution of the zero and high pressure deformation torsion indicates a strong pressure dependence of the shear band formation process.

\section{Special Properties of Severely Deformed Metallic Glasses}

\subsection{Enhanced ductility and changed mechanical be- havior}

Metallic glasses have several advantageous mechanical, chemical and structural characteristics, most of these features are based on the homogeneity of the microstructure down to atomic scale. Therefore, the extremely localized shear band formation does not interfere with any microstructure in BMGs and often lead to the fracture along the formed straight and single shear band under stress. ${ }^{11)}$ Interaction between soft, atomic size inhomogeneities and the homogeneous external stress field in metallic glasses can induce stress gradients and a less localized shear pattern which is incompatible with formation of straight shear bands. Therefore the atomic size inhomogeneities can effectively promote the formation of multiple shear bands and induce macroscopic plasticity in these amorphous alloys. In a recent study, Joo et al. has reported yield stress drop, work hardening and the appearance of tensile ductility in room temperature HPT deformed Zr-based BMGs (Fig. 17). They revealed by positron annihilation lifetime measurements that vacancy clusters with size of a few atoms appear as atomic level inhomogeneities in the HPT process. ${ }^{98)}$ In agreement, Ebner
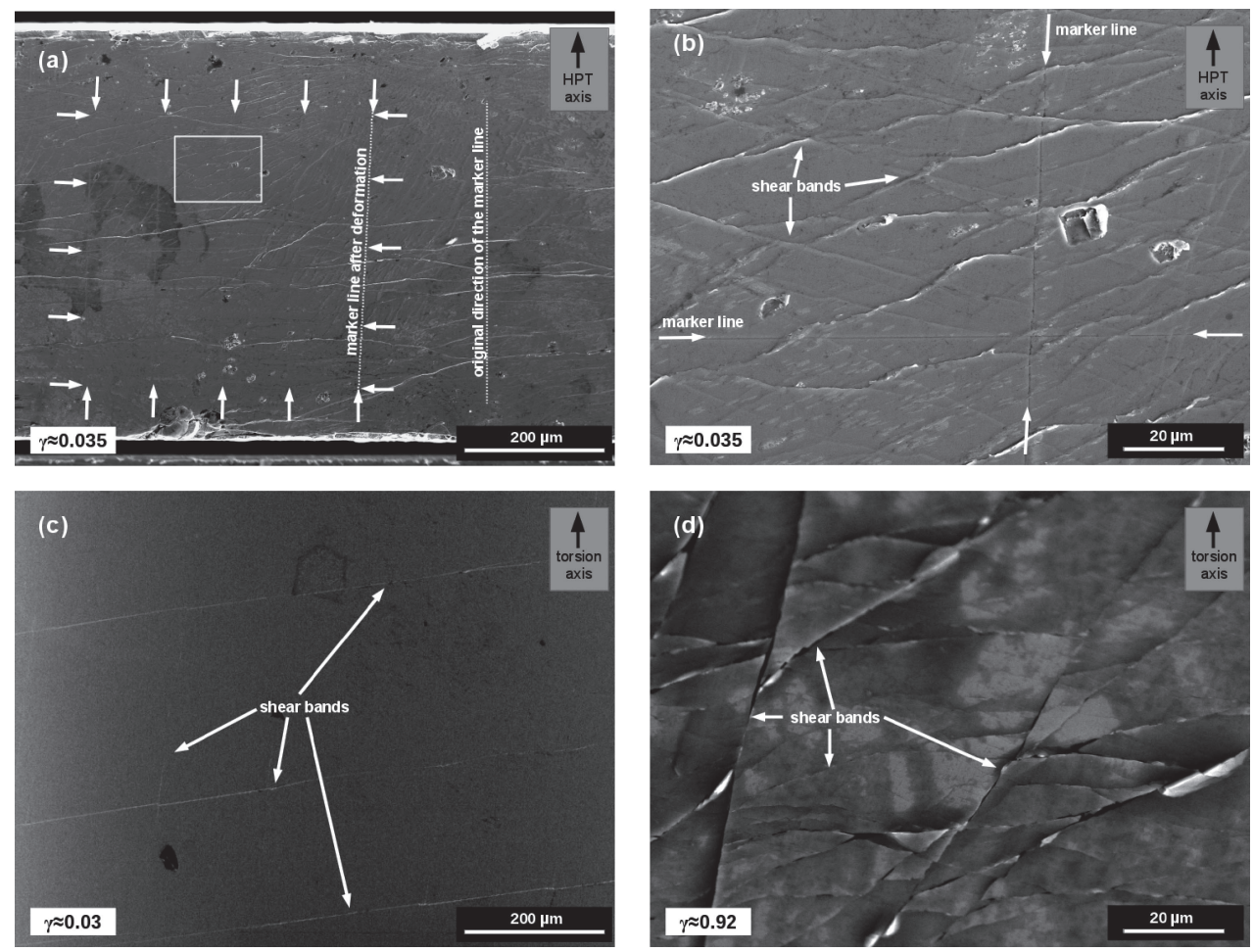

Fig. 16 (a) Scanning electron microscopy image of an opened up interior surface of an HPT deformed Vitreloy $1 \mathrm{~b}$ BMG disk with average shear deformation of $\gamma_{\mathrm{pl}}=0.035$. The ends of the marker lines are indicated by arrows. ${ }^{97)}$ (b) Enlarged view of the rectangular area indicated in (a) showing the shear bands and the marker lines. ${ }^{97)}$ For comparison, the scanning electron microscopy image of the free surface of Vitreloy 1b BMG samples after free-end torsion deformation with (c) $\gamma_{\mathrm{pl}}=0.03$ and (d) $\gamma_{\mathrm{pl}}=0.92$ shear strain. 


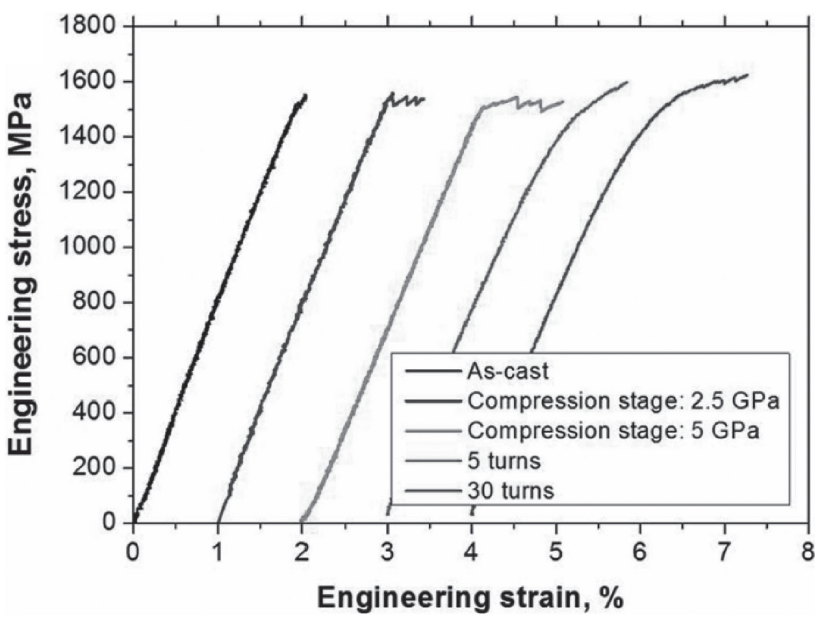

Fig. 17 Stress strain curves of Zr-based as-cast and HPT-processed BMGs. ${ }^{98)}$

et al. revealed an increase in the mean atomic volume and increase in the microscopic scale inhomogeneities in HPT deformed BMG samples. ${ }^{99)}$ Feng et al. has pointed out in a molecular dynamic simulation that HPT induce structural evolution on atomic scale and decrease the number of the strongly bounded environment having five-fold symmetry. ${ }^{100)}$ In contrast, a La-based alloy processed by room temperature HPT (which is about $0.7 \mathrm{Tg}$ for the La-based BMG) deformation resulted in no tensile plasticity, however significant increase in the thermal conductivity and minor increase in the fracture strength were observer. ${ }^{101)}$ As an effect of the formation of short but multiple shear bands, room temperature HPT deformation of a $\mathrm{ZrCuAlFeDy} \mathrm{BMG}$ lead to slight increase in the strain rate sensitivity parameter and visible change of the deformation from localized to homogeneous mode near nanoindentation imprints. ${ }^{102)}$

As an alternative method, second phase containing BMGs can be also produced to favor shear band multiplication. However, these composites often become more brittle, than their fully amorphous counterparts. To overcome the problem of the brittleness, few nanometer size soft particles with good particle-matrix bonding are preferred in these systems. HPT and thermal treatments are capable to produce such nanostructure in e.g. Al-based primary crystallizing metallic glasses (see Section 3). As an alternative method, Sun et al. have produced nanocomposite material by shearing half-half disks of a high stability $\mathrm{Zr}$-based BMG and $\mathrm{Cu}$ by HPT up to $\mathrm{N}=50$ rotations. ${ }^{103)}$

\subsection{Hydrogen storage of Mg-based glassy alloys}

Hydrogen as the most abundant element can serve as potential energy carrier, since it can generate 3-4 times more energy per mass compared to the conventional sources. In order to commercialize the hydrogen energy, production, transmission, conversion and usage must achieve a threshold of effectiveness. Hydrogen storage in the solid state seems to be a promising solution, however, substantial technological challenges must be solved if hydrogen is to be applied as a fuel as a part of the hydrogen-powered energy grid. ${ }^{104)}$ In the last couple of decades systems like simple and complex metallic hydrides resulted in a great interest, since they exhibit high gravimetric and volumetric hydrogen capaci-
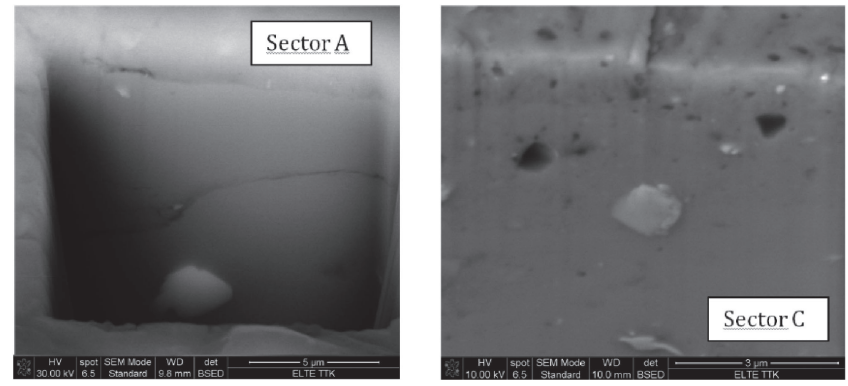

Fig. 18 Scanning electron micrographs taken from the inner surface of the ion-milled notches corresponding to center and the edge of the HPTdisk. $^{120)}$

ties. ${ }^{105,106)}$ Among them magnesium hydride is considered as one of the most promising hydrogen storage materials, mainly because of high storage capacity (7.6 mass\%), lightweight and low cost. ${ }^{107)}$ In order to improve the sluggish kinetics of commercial magnesium, nano-sized $\mathrm{Mg}$ powders have been synthesized by ball milling world-wide. ${ }^{108-114)}$ Improved hydrogen storage capacity and kinetics on bulky Mg-based crystalline samples can also be achieved by extensive plastic deformation during HPT. ${ }^{115-119)}$ Edalati et al. have shown that hydrogen absorption becomes prominent and the sorption rate is significantly increased when pure $\mathrm{Mg}$ is subjected to the HPT process. ${ }^{116)}$ Nevertheless, all attempts to bring the desorption temperature of nanocrystalline magnesium or $\mathrm{Mg}$-based compounds down to $150^{\circ} \mathrm{C}$ have so far been unsuccessful.

When fully amorphous $\mathrm{Mg}_{65} \mathrm{Ni}_{20} \mathrm{Cu}_{5} \mathrm{Y}_{10}$ metallic glass compacts were subjected to heavy shear deformation by high pressure torsion until different amount of ultimate strain, a deformation dependent microstructure develops ${ }^{120}$ ) as it is presented in Fig. 18. The high magnification scanning electron microscope images taken from the inner surface of ion-milled notches close to the torsion axis is characterized only by a few crystalline blocks with a maximum diameter of $\sim 1 \mu \mathrm{m}$ (Sector A), while the most deformed perimeter is abundant in crystals ranging from 30 to $500 \mathrm{~nm}$ embedded in the amorphous matrix (Sector C). Based on elemental analysis, it is found that these blocks contain mainly $\mathrm{Mg}_{2} \mathrm{Ni}$ crystals. At the same time, the hardness of the alloy increases during the HPT process due to the formation of harder $\mathrm{Mg}_{2} \mathrm{Ni}$ particles. ${ }^{121)}$ High-pressure calorimetry measurements revealed the hydrogen absorption in the fully amorphous alloy $\left(\mathrm{T}_{\mathrm{abs}} \sim 350-420 \mathrm{~K}\right)$ occurs at a significantly lower temperature compared to the crystallized state $\left(\mathrm{T}_{\mathrm{abs}} \sim 480\right.$ $550 \mathrm{~K}$ ), see Fig. 19. For the crystallized sample containing several compound phases (such as $\mathrm{Mg}_{2} \mathrm{Ni}, \mathrm{Mg}_{6} \mathrm{Ni}, \mathrm{Mg}_{2} \mathrm{Cu}$, $\mathrm{Mg}$, Ni and $\mathrm{Mg}_{24} \mathrm{Y}_{5}$, see Ref. 120)), the exothermic peak can be assigned to the formation of a solid solution of hydrogen mainly into the $\mathrm{Mg}_{2} \mathrm{Ni}$ phase. A less intense $\mathrm{H}$-absorption peak characterizes the thermogram of the amorphous alloy, however the transformation occurs at temperatures below the glass transition, $\mathrm{T}_{\mathrm{g}}{ }^{121}{ }^{12}$ The decrease in $\mathrm{T}_{\mathrm{abs}}$ is governed by enhanced absorption kinetics, in line with its structural characteristics such as lower atomic density and excess free volume, ${ }^{122)}$ resulting in faster hydrogen diffusion and shorten diffusion distances. When the $\mathrm{Mg}_{65} \mathrm{Ni}_{20} \mathrm{Cu}_{5} \mathrm{Y}_{10}$ metallic glass is subjected to severe shear deformation by HPT, the 


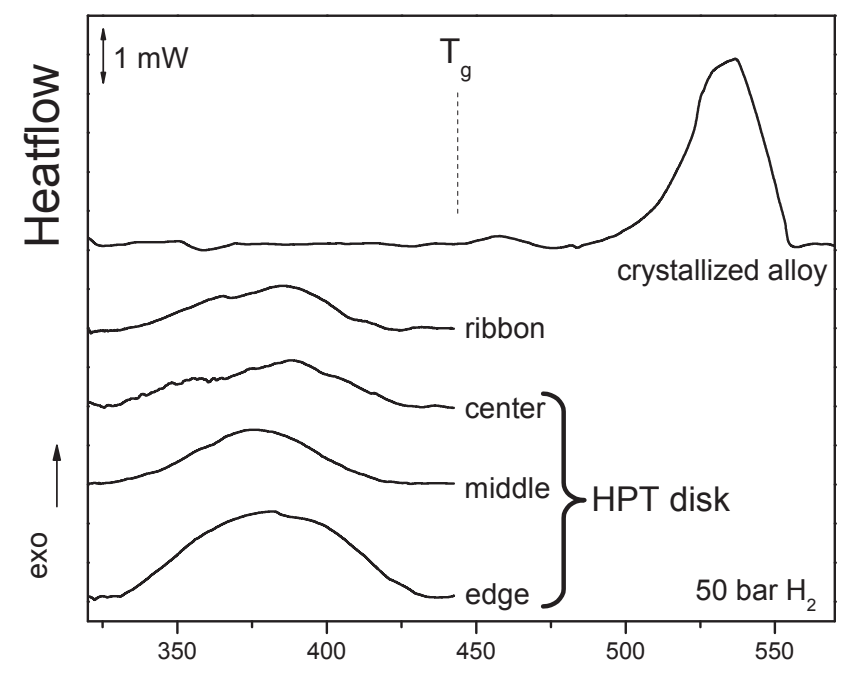

\section{Temperature $(\mathrm{K})$}

Fig. 19 High-pressure calorimetry measurements on the reference $\mathrm{Mg}_{65} \mathrm{Ni}_{20} \mathrm{Cu}_{5} \mathrm{Y}_{10}$ crystalline sample, the fully amorphous ribbon and different deformation states of the HPT-disk. ${ }^{121)}$

hydrogen absorption occurs at a remarkable low temperature range $\left(\mathrm{T}_{\mathrm{abs}} \sim 310-420 \mathrm{~K}\right)$, similarly to the monolithic glass, as was also observed in a HPT-deformed $\mathrm{Mg}_{65} \mathrm{Ce}_{10} \mathrm{Ni}_{20} \mathrm{Cu}_{5}$ nanoglass. ${ }^{123)}$ At the same time the enthalpy of hydride formation increases considerably at the perimeter of the HPTdisk due to the formation of deformation induced $\mathrm{Mg}_{2} \mathrm{Ni}$ crystals that can provide additional $\mathrm{H}$-sites and increase the storage capacity. However, it is noted that despite the favorable sorption temperature, the total amount of absorbed hydrogen in Mg-based HPT-deformed metallic glasses is significantly lower than that of crystalline magnesium hydride. ${ }^{120,123)}$

\section{Acknowledgements}

This work was completed in the ELTE Institutional Excellence Program (1783-3/2018/FEKUTSRAT) supported by the Hungarian Ministry of Human Capacities.

\section{REFERENCES}

1) A. Inoue: Acta Mater. 48 (2000) 279-306.

2) M. Miller and P. Liaw: Bulk Metallic Glasses, (Springer, Berlin, 2008).

3) Y.Q. Cheng and E. Ma: Prog. Mater. Sci. 56 (2011) 379-473.

4) D.B. Miracle, T. Egami, K.M. Flores and K.F. Kelton: MRS Bull. 32 (2007) 629-634.

5) M.M. Trexler and N.N. Thadhani: Prog. Mater. Sci. 55 (2010) 759839.

6) A.L. Greer and E. Ma: MRS Bull. 32 (2007) 611-619.

7) A.R. Yavari, J.J. Lewandowski and J. Eckert: MRS Bull. 32 (2007) 635-638.

8) C.A. Schuh, T.C. Hufnagel and U. Ramamurty: Acta Mater. 55 (2007) 4067-4109.

9) F. Spaepen: Scr. Mater. 54 (2006) 363-367.

10) Z.Y. Liu, Y. Yang and C.T. Liu: Acta Mater. 61 (2013) 5928-5936.

11) A.L. Greer, Y.Q. Cheng and E. Ma: Mater. Sci. Eng. R 74 (2013) 71 132.

12) H. Chen, Y. He, G.J. Shiflet and S.J. Poon: Nature 367 (1994) 541 -
543.

13) Y. Zhang and A.L. Greer: Appl. Phys. Lett. 89 (2006) 071907.

14) M. Stolpe, J.J. Kruzic and R. Busch: Acta Mater. 64 (2014) 231-240.

15) A.S. Argon: Acta Metall. 27 (1979) 47-58.

16) T.G. Nieh and J. Wadsworth: Scr. Mater. 54 (2006) 387-392.

17) W.L. Johnson, M.D. Demetriou, J.S. Harmon, M.L. Lind and K. Samwer: MRS Bull. 32 (2007) 644-650.

18) C.A. Angell: MRS Bull. 33 (2008) 544-555.

19) Y. Zhang, W.H. Wang and A.L. Greer: Nat. Mater. 5 (2006) 857-860

20) Y.H. Liu, G. Wang, R.J. Wang, D.Q. Zhao, M.X. Pan and W.H. Wang: Science 315 (2007) 1385-1388.

21) L.Q. Xing, Y. Li, K.T. Ramesh, J. Li and C. Hufnagel: Phys. Rev. B 64 (2001) 180201.

22) X.K. Xi, D.Q. Zhao, M.X. Pan, W.H. Wang, Y. Wu and J.J. Lewandowski: Phys. Rev. Lett. 94 (2005) 125510.

23) R.J. Herbert, N. Boucharat, J.H. Perepezko, H. Rösner and G. Wilde: J. Alloys Compd. 434-435 (2007) 252-254.

24) J. Sort, D.C. Ile, A.P. Zhilyaev, A. Concustell, T. Czeppe, M. Stoica, S. Suriñach, J. Eckert and M.D. Baró: Scr. Mater. 50 (2004) 12211225 .

25) K. Edalati, I. Fujita, X. Sauvage, M. Arita and Z. Horita: J. Alloys Compd. 779 (2019) 394-398.

26) B.B. Straumal, O.A. Kogtenkova, R.Z. Valiev, P. Zieba and B. Baretzky: Diffusion Found. 5 (2015) 95-108.

27) T. Czeppe, G.F. Korznikova, P. Ochin, A.V. Korznikov, N.Q. Chinh and A. Sypien: J. Phys. Conf. Ser. 98 (2008) 062035.

28) R.Z. Valiev, D.V. Gunderov, A.P. Zhilyaev, A.G. Popov and V.G. Pushin: J. Metast. Nanocryst. Mater. 22 (2004) 21-26.

29) R.Z. Valiev, R.K. Ishlamgaliev and I.V. Alexandrov: Prog. Mater. Sci. 45 (2000) 103-189.

30) K. Edalati and Z. Horita: Mater. Sci. Eng. A 652 (2016) 325-352.

31) A.P. Zhilyaev and T.G. Langdon: Prog. Mater. Sci. 53 (2008) 893979.

32) R.Z. Valiev, A.P. Zhilyaev and T.G. Langdon: Bulk Nanostructured Materials: Fundamentals and Applications, (Wiley, Hoboken, 2014).

33) B.B. Straumal, A.A. Mazilkin, B. Baretzky, G. Schütz, E. Rabkin and R.Z. Valiev: Mater. Trans. 53 (2012) 63-71.

34) N. Boucharat, H. Rösner and G. Wilde: J. Non-Crsyt. Solids 354 (2008) 592-596.

35) Á. Révész, E. Schafler and Zs. Kovács: Appl. Phys. Lett. 92 (2008) 011910.

36) Y.P. Song, E.Y. Yoon, D.J. Lee, J.H. Lee and H.S. Kim: Mater. Sci. Eng. A 528 (2011) 4840-4844.

37) M. Hafok and R. Pippan: Scr. Mater. 56 (2007) 757-760.

38) W. Klement, R.H. Willens and P. Duwez: Nature 187 (1960) 869-870.

39) W.L. Johnson: MRS Bull. 24 (1999) 42-56.

40) J.Y. Huang, Y.T. Zhu, X.Z. Liao and R.Z. Valiev: Philos. Mag. Lett. 84 (2004) 183-190.

41) Á. Révész, J.L. Lábár, S. Hóbor, A.P. Zhilyaev and Zs. Kovács: J. Appl. Phys. 100 (2006) 103522.

42) Zs. Kovács, S. Hóbor, P.J. Szabó, J. Lendvai, A.P. Zhilyaev and Á. Révész: Mater. Sci. Eng. A 449-451 (2007) 1139-1142.

43) Á. Révész, Zs. Kovács, P.J. Szabó, E. Schafler, L.K. Varga and S. Hóbor: Phys. Status Solidi A 207 (2010) 1185-1189.

44) Y.F. Sun, T. Nakamura, Y. Todaka, M. Umemoto and N. Tsuji: Intermetallics 17 (2009) 256-261.

45) F.Q. Meng, K. Tsuchiya and Y. Yokoyama: Intermetallics 37 (2013) $52-58$.

46) F. Meng, K. Tsuchiya, Q. Mei, B. Jiang and Y. Yokoyama: Mater. Trans. 54 (2013) 1224-1227.

47) R.V. Sundeev, A.M. Glezer and A.V. Shalimova: Mater. Lett. 133 (2014) 32-34.

48) A.M. Glezer, R.V. Sundeev and A.V. Shalimov: Rev. Adv. Mater. Sci. 54 (2018) 93-105.

49) L. Kramer, Y. Champion and R. Pippan: Sci. Rep. 7 (2017) 6651.

50) L. Kramer, Y. Champion, K.S. Kormout, V. Maier-Kiener and R. Pippan: Intermetallics 94 (2018) 172-178.

51) A. Inoue: Prog. Mater. Sci. 43 (1998) 365-520.

52) Zs. Kovács, P. Henits, A.P. Zhilyaev and Á. Révész: Scr. Mater. 54 (2006) 1733-1737.

53) Á. Révész, S. Hóbor, P.J. Szabó, A.P. Zhilyaev and Zs. Kovács: Mater. 
Sci. Eng. A 460-461 (2007) 459-463.

54) B. Zheng, Y. Zhou, S.N. Mathaudhu, R.Z. Valiev, C.Y.A. Tsao, J.M. Schoenung and E.J. Lavernia: Scr. Mater. 86 (2014) 24-27.

55) Z.C. Zhong, X.Y. Jiang and A.L. Greer: Mater. Sci. Eng. A 226-228 (1997) 531-535.

56) Y. He, S.J. Pooh and G.J. Shiflet: Science 241 (1988) 1640-1642.

57) A. Inoue, K. Ohtera, A.P. Tsai and T. Masumoto: Jpn. J. Appl. Phys. 27 (1988) L280-L282.

58) A. Inoue, K. Ohtera, A.P. Tsai and T. Masumoto: Jpn. J. Appl. Phys. 27 (1988) L479-L482.

59) Zs. Kovács, P. Henits, L.K. Varga, E. Schafler and Á. Révész: J. Alloys Compd. 561 (2013) 5-9

60) Zs. Kovács, P. Henits, A. Zhilyaev, N.Q. Chinh and Á. Révész: Mater. Sci. Forum 519-521 (2006) 1329-1334.

61) P. Henits, Zs. Kovács, E. Schaffler, L.K. Varga, J.L. Lábár and Á. Révész: J. Alloys Compd. 504S (2010) S91-S94.

62) P. Henits, Á. Révész, A.P. Zhilyaev and Zs. Kovács: J. Alloys Compd. 461 (2008) 195-199.

63) P. Henits, Á. Révész, E. Schafler, P.J. Szabó, J.L. Lábár, L.K. Varga and Zs. Kovács: J. Mater. Res. 25 (2010) 1388-1397.

64) P. Henits, Zs. Kovács, L.K. Varga and Á. Révész: J. Phys. Conf. Ser. 144 (2009) 012095.

65) P. Henits, Á. Révész, L.K. Varga and Zs. Kovács: Intermetallics 19 (2011) 267-275.

66) S. Hóbor, Zs. Kovács and Á. Révész: J. Appl. Phys. 106 (2009) 023531 .

67) S. Hóbor, Zs. Kovács and Á. Révész: J. Alloys Compd. 495 (2010) 352-355.

68) Á. Révész, E. Schafler and Zs. Kovács: Appl. Phys. Lett. 92 (2008) 011910 .

69) S. Hóbor, Á. Révész, P.J. Szabó, A.P. Zhilyaev, V. Kovács Kis, J.L. Lábár and Zs. Kovács: J. Appl. Phys. 104 (2008) 033525.

70) N. Van Steenberge, S. Hóbor, S. Surinach, A.P. Zhilyaev, F. Houdellier, F. Mompiu, M.D. Baró, Á. Révész and J. Sort: J. Alloys Compd. 500 (2010) 61-67.

71) R.B. Figueiredo, P.H.R. Pereira, M.T.P. Aguilar, P.R. Cetlin and T.G. Langdon: Acta Mater. 60 (2012) 3190-3198.

72) P.H.R. Pereira, R.B. Figueiredo, P.R. Cetlin and T.G. Langdon: IOP Conf. Series Mater. Sci. Eng. 63 (2014) 012041.

73) K. Edalati, R. Miresmaeili, Z Horita, H. Kanayama and R. Pippan: Mater. Sci. Eng A 528 (2011) 7301-7305.

74) K. Edalati, Y. Hashiguchi, P.H.R. Pereira, Z. Horita and T.G. Langdon: Mater. Sci. Eng. A 714 (2018) 167-171.

75) P. Henits, Á. Révész and Zs. Kovács: Mech. Mater. 50 (2012) 81-87.

76) Zs. Kovács, E. Schafler and Á. Révész: J. Mater. Res. 23 (2008) 3409-3414.

77) J.J. Lewandowski and A.L. Greer: Nat. Mater. 5 (2006) 15-18.

$78)$ S. Hóbor, Zs. Kovács, A.P. Zhilyaev, L.K. Varga, P.J. Szabó and Á. Révész: J. Phys. Conf. Ser. 240 (2010) 012153.

79) S. Hóbor, Zs. Kovács and Á. Révész: J. Alloys Compd. 509 (2011) 8641-8648.

80) H. Asgharzadeh, S.-H. Joo, J.-K. Lee and H.S. Kim: J. Mater. Sci. 50 (2015) 3164-3174.

81) Zs. Kovács, E. Schafler, V.K. Kis, P.J. Szommer and Á. Révész: J. Non-Cryst. Solids 498 (2018) 25-31.

82) B. Sarac, F. Spieckermann, A. Rezvan, C. Gammer, L. Krämer, J.T. Kim, J. Keckes, R. Pippan and J. Eckert: J. Alloys Compd. (2019) in press. https://doi.org/10.1016/j.jallcom.2019.01.063.

83) R.V. Sundeev, A.M. Glezer, A.P. Menushenkov, A.V. Shalimova, O.V. Chernysheva and N.V. Umnova: Mater. Des. 135 (2017) 77-83.

84) D.V. Gunderov, V.Yu. Slesarenko, A.A. Churakova, A.V. Lukyanov, E.P. Soshnikova, V.G. Pushin and R.Z. Valiev: Intermetallics 66 (2015) 77-81.

85) D.V. Gunderov, E.V. Boltynjuk, E.V. Ubyivovk, A.V. Lukyanov, A.A. Churakova, A.R. Kilmametov, Y.S. Zamula and R.Z. Valiev: J. Alloys Compd. 749 (2018) 612-619.

86) Y. Suzuki, J. Haimovich and T. Egami: Phys. Rev. B 35 (1987) $2162-$ 2168.

87) H.F. Poulsen, J.A. Wert, J. Neuefeind, V. Honkimaki and M. Daymond: Nat. Mater. 4 (2005) 33-36.

88) R.T. Ott, M.J. Kramer, M.F. Besser and D.J. Sordelet: Acta Mater. 54
(2006) 2463-2471.

89) W. Dmowski and T. Egami: Adv. Eng. Mater. 10 (2008) 1003-1006.

90) W. Dmowski, Y. Yokoyama, A. Chuang, Y. Ren, M. Umemoto, K. Tsuchiya, A. Inoue and T. Egami: Acta Mater. 58 (2010) 429-438.

91) Á. Révész, P. Henits and Zs. Kovács: J. Alloys Compd. 495 (2010) 338-340.

92) N. Adachi, Y. Todaka, Y. Yokoyama and M. Umemoto: Mater. Sci. Eng. A 627 (2015) 171-181.

93) Zs. Kovács, L.S. Tóth and J. Lendvai: J. Alloys Compd. 542 (2012) 85-89.

94) M. Ezzeldien, Zs. Kovács, J. Lendvai, F. Chmelík and K. Máthis: J. Alloys Compd. 577 (2013) 25-29.

95) Zs. Kovacs, M. Ezzeldien, K. Mathis, P. Ispanovity, F. Chmelık and J. Lendvai: Acta Mater. 70 (2014) 113-122.

96) Zs. Kovacs, M. Ezzeldien, N.Q. Chinh, Gy. Radnoczi and J. Lendvai: J. Alloys Compd. 708 (2017) 301-307.

97) Zs. Kovács, E. Schafler, P. Szommer and Á. Révész: J. Alloys Compd. 593 (2014) 207-212.

98) S.-H. Joo, D.-H. Pi, A.D.H. Setyawan, H. Kato, M. Janacek, Y.C. Kim, S. Lee and H.S. Kim: Sci. Rep. 5 (2015) 9660.

99) C. Ebner, B. Escher, C. Gammer, J. Eckert, S. Pauly and C. Rentenberge: Acta Mater. 160 (2018) 147-157.

100) S.D. Feng, W. Jiao, Q. Jing, L. Qi, S.P. Pan, G. Li, M.Z. Ma, W.H. Wang and R.P. Liu: Sci. Rep. 6 (2016) 36627.

101) J. Guo, S.-H. Joo, D. Pi, W. Kim, Y. Song, H.S. Kim, X. Zhang and D. Kong: Adv. Eng. Mater. (2018) in press. https://doi.org/10.1002/ adem.201800918.

102) E.V. Boltynjuk, D.V. Gunderov, E.V. Ubyivovk, M.A. Monclús, L.W. Wang, J.M. Molina-Aldareguia, A.I. Tyurin, A.R. Kilmametov, A.A. Churakova, A.Y. Churyumov and R.Z. Valiev: J. Alloys Compd. 747 (2018) 595-602.

103) Y.F. Sun, H. Fujii, N. Tsuji, Y. Todaka and M. Umemoto: J. Alloys Compd. 492 (2010) 149-152.

104) A.M. Abdalla, S. Hossain, O.B. Nisfindy, A.T. Azad, M. Dawood and A.K. Azad: Energy Convers. Manage 165 (2018) 602-627.

105) L. Schlapbach and A. Züttel: Nature 414 (2001) 353-358.

106) R.A. Varin, T. Czujko and Z.S. Wronski: Nanomaterials for Solid State Hydrogen Storage, (Springer, New York, 2009).

107) T. Sadhasivam, H.-T. Kim, S. Jung, S.-H. Roh, J.-H. Park and H.-Y. Jung: Renew. Sustain. Energy Rev. 72 (2017) 523-534.

108) R.A. Varin, T. Czujko, Ch. Chiu and Z. Wronski: J. Alloys Compd. 424 (2006) 356-364.

109) L. Zaluski, A. Zaluska, P. Tessier, J.O. Ström-Olsen and R. Schulz: Mater. Sci. Forum 225 (1996) 853-858.

110) G. Liang, S. Boily, J. Huot, A. Van Neste and R. Schulz: J. Alloys Compd. 267 (1998) 302-306.

111) M. Danaie and D. Mitlin: J. Alloys Compd. 476 (2009) 590-598.

112) M. Porcu, A.K. Petford-Long and J.M. Sykes: J. Alloys Compd. 453 (2008) 341-346.

113) V. Fuster, G. Urretavizcaya and F.J. Castro: J. Alloys Compd. 481 (2009) 673-680.

114) D. Fátay, Á. Révész and T. Spassov: J. Alloys Compd. 399 (2005) 237-241.

115) Y. Kusadome, K. Ikeda, Y. Nakamori, S. Orimo and Z. Horita: Scr. Mater. 57 (2007) 751-753.

116) K. Edalati, A. Yamamoto, Z. Horita and T. Ishihara: Scr. Mater. 64 (2011) 880-883.

117) D.R. Leiva, A. Moreira Jorge, T.T. Ishikawa, J. Huot, D. Fruchart, S. Miraglia, C.S. Kiminami and W.J. Botta: Adv. Eng. Mater. 12 (2010) 786-792.

118) Á. Révész, Zs. Kánya, T. Verebélyi, P.J. Szabó, A.P. Zhilyaev and T. Spassov: J. Alloys Compd. 504 (2010) 83-88.

119) T. Hongo, K. Edalati, M. Arita, J. Matsuda, E. Akiba and Z. Horita: Acta Mater. 92 (2015) 46-54.

120) Á. Révész, Á. Kis-Tóth, L.K. Varga, E. Schafler, I. Bakonyi and T. Spassov: Int. J. Hydrogen Energy 37 (2012) 5769-5776.

121) Á. Révész, Á. Kis-Tóth, P. Szommer and T. Spassov: Mater. Sci. Forum 729 (2013) 74-79.

122) F. Spaepen: Acta Metall. 25 (1977) 407-415.

$123)$ C. Xu, H.-J. Lin, K. Edalati, W. Li, L. Li and Y. Zhu: Scr. Mater. 152 (2018) 137-140. 